\title{
Níveis de Cálcio em Rações de Frangos de Corte na Fase Inicial Suplementadas com Fitase 1
}

\author{
Neudi Artemio Schoulten ${ }^{2}$, Antônio Soares Teixeira ${ }^{3}$, Rilke Tadeu Fonseca de Freitas ${ }^{3}$, Antônio \\ Gilberto Bertechini ${ }^{3}$, Ademir José Conte ${ }^{4}$, Hunaldo Oliveira Silva ${ }^{5}$
}

RESUMO - Com o objetivo de avaliar níveis de cálcio em rações suplementados com enzima fitase para frangos de 1 a 21 dias de idade, foi conduzido um experimento com 600 pintos de um dia da linhagem Hubbard-MPK. As aves foram distribuídas em um delineamento inteiramente casualizado, arranjo fatorial cinco x dois (níveis de cálcio x sexos), com três repetições e 20 aves por parcela. A ração basal, com $0,54 \%$ de fósforo total e 600 unidades de fitase $/ \mathrm{kg}$, foi balanceada para atender às exigências nutricionais das aves conforme o NRC (1994), exceto para o cálcio, cujos níveis foram 0,$46 ; 0,67 ; 0,88 ; 1,09$ e 1,30\%. Aos 14 dias, duas aves de cada tratamento foram transferidas para gaiolas de metabolismo para coleta total das excretas e aos 21 dias, duas aves de cada tratamento foram abatidas para retirada da tíbia esquerda para análises posteriores. Os machos apresentaram maior consumo e ganho de peso, sendo que este apresentou redução linear conforme o nível de cálcio foi elevado. Os níveis de 0,67 e $0,71 \%$ resultaram em melhor digestibilidade da matéria seca e maior retenção de nitrogênio, respectivamente. As fêmeas apresentaram teores de cinzas e cálcio, na tíbia, superiores aos dos machos ( 1,68 e 2,34\%, respectivamente). O nível de $0,55 \%$ de cálcio proporcionou a máxima deposição de cinzas (51,5\%), enquanto o nível de $0,59 \%$, a máxima calcificação (17,8\%). A deposição de fósforo apresentou efeito quadrático, em função dos níveis de cálcio, sendo que o nível de $0,75 \%$ proporcionou a maior deposição (10,8\%), e a deposição de manganês foi reduzida linearmente com a elevação do nível de cálcio na ração. Conclui-se que níveis elevados de cálcio em rações suplementadas com fitase afetaram negativamente o ganho de peso, a deposição de fósforo e manganês na tíbia e que os baixos níveis prejudicaram a digestibilidade da matéria seca e a retenção de nitrogênio.

Palavras-chave: desempenho, digestibilidade, exigência, fósforo, cinza, manganês, mineralização, zinco

\section{Levels of Calcium in Broiler Diets Supplemented With Phytase in the Initial Phase}

ABSTRACT - With the objective of evaluating increasing levels of calcium in diets supplemented with the enzyme phytase for chickens from 1 to 21 days of age, an experiment was conducted using 600 1-d old Hubbard-MPK strain chicks. The broilers were allotted to a completely randomized design, factorial arrangement five $\mathrm{x}$ two (levels of calcium $\mathrm{x}$ sexes), three replicates and 20 birds per plot. The basal ration with $0.54 \%$ total phosphorus and 600 units of phytase $/ \mathrm{kg}$, was formulated to meet the nutritional requirements of the broilers, according to NRC (1994), except for calcium, whose levels were 0.46; 0.67; 0.88; 1.09 and $1.30 \%$. At 14 days, two chicks of each treatment were transferred to metabolism cages for total collection of the excreta during four consecutive days. At 21 days of age, two broilers from each treatment were slaughtered for removal of the left tibia for subsequent analyses. The males presented higher fed intake and weight gain, and shown a linear reduction as the level of calcium was increased. The levels of 0.67 and $0.71 \%$ presented better digestibility of dry matter and higher nitrogen retention, respectively. The females presented content of ashes and calcium in the tibia higher than those of males ( 1.68 and $2.34 \%$ respectively). The level of $0.55 \%$ of calcium in the diets provided the maximum deposition of ashes $(51.5 \%)$ while the level of $0.59 \%$ was enabled to reach the maximum calcification (17.8\%). Phosphorus deposition showed quadratic effect in relation to increasing levels of calcium in the diets, and $0.75 \%$ of calcium provided to reach the largest deposition $(10.8 \%)$, while deposition of manganese was reduced linearly with the increasing levels of calcium in the diets. It was concluded that high levels of calcium in the diets supplemented with phytase decreased weight gain and shown negative effect on the phosphorus and manganese deposition in the broilers tibia from one to 21 days of age. Low levels of calcium impaired the digestibility of dry matter and nitrogen retention of diets of broilers one to 21 day old broilers.

Key Words: digestibility, performance, phosphorus, requirement, ash, manganese, mineralization, zinc

\footnotetext{
1 Parte da dissertação apresentada pelo primeiro autor ao DZO/UFLA.

2 Professor da Escola Agrotécnica Federal de Rio do Sul -SC. Bolsista da CAPES/PICDTEC. E.mail: neudi@navinet.com.br

3 Professor da UFLA/Departamento de Zootecnia. E.mail: assoarest@ufla.br

4 Professor da Escola Agrotécnica Federal de Cuiabá - MT. E.mail: ajconte@zaz.com.br

5 Estudante de Doutorado DZO/UFLA. hunald@ufla.br
} 


\section{Introdução}

A ração de frangos de corte baseia-se em alimentos de origem vegetal, os quais, segundo Rostagno (1998), apresentam de 45 a 75\% de seu conteúdo de fósforo indisponível para animais monogástricos porque este elemento está complexado à molécula do fitato. Além do fósforo, a molécula do fitato pode formar quelatos com outros minerais, mono e divalentes, como cálcio, zinco, cobre, ferro, potássio, magnésio e manganês. A utilização da fitase não só reduz a necessidade de suplementação com fósforo, mas também de outros minerais que podem ser liberados para a absorção (Sebastian et al., 1996a). O efeito da fitase sobre a disponibilidade do Fósforo já é bastante estudado e relativamente bem estabelecido (Borges, 1997), o que não ocorre com os outros minerais complexados com o fitato, principalmente cálcio.

Níveis de cálcio e fósforo na ração para frangos influenciam a utilização do fósforo fítico (Edwards Jr. \& Veltmann, 1983). Aves consumindo rações com baixos níveis de fósforo e cálcios inorgânicos apresentam maior capacidade para hidrolisar o fitato do que aquelas que recebem níveis altos (Denbow et al., 1995). A relação cálcio/fósforo influencia a atividade da fitase, que é reduzida com a elevação do nível de cálcio da ração (Qian, et al., 1997). Em rações práticas suplementadas com fitase, esta relação parece mais crítica do que quantidades individuais destes minerais. A elevação da proporção de cálcio/ fósforo reduz significativamente o desempenho de frangos em rações à base de milho e farelo de soja, suplementadas com fitase (Leeson, 1999), provavelmente devido à reação do cálcio com o ácido fítico, formando o fitato de cálcio, que precipita e não pode ser hidrolisado pela fitase. Ao centrifugar o conteúdo intestinal de frangos de corte que consumiram rações com alto nível de cálcio (acima de 1,53\%), Shafey et al. (1991) verificaram que 70 a $92 \%$ do cálcio, ferro, magnésio e zinco estavam na forma insolúvel e sugerem que a elevação do $\mathrm{pH}$ intestinal, em função da elevação do nível de cálcio, reduz a fração solúvel de minerais e a sua disponibilidade para absorção. Para maior solubilização do fitato, énecessário manter os níveis de fósforo e cálcio inorgânicos nos limites mínimos necessários (Mitchell \& Edwards Jr., 1996a), indicando que os níveis destes minerais devem ser reduzidos, quando a fitase for empregada durante a formulação (Ballam et al., 1984). A mineralização óssea de frangos de corte de 1 a 21 dias de idade, submetidos à ração à base de milho e farelo de soja, com $0,51 \%$ de fósforo total, suplementada com $66 \mathrm{mg}$ de vitamina D e $600 \mathrm{FTU} / \mathrm{kg}$ de ração, foi afetada pelos níveis de cálcio da ração com resposta quadrática, ocorrendo redução dos teores de cinza dos ossos à medida que o nível de cálcio foi elevado de 0,56 para 1,02\% (Qian et al., 1997).

O cálcio tem sido alvo de vários trabalhos, nos quais se procura avaliar a exigência nutricional deste elemento, considerando as diferentes linhagens, o sexo, o consumo de ração e as suas relações com outros minerais da ração, principalmente o fósforo. Conforme o NRC (1994), a exigência de cálcio para frangos é de $1 \%$ de 1 a 21 dias e $0,90 \%$ de 22 a 42 dias, para rações com $3200 \mathrm{kcal} / \mathrm{kg}$. Porém, Karunajeewa (1976) concluiu que, para a fase de crescimento, $0,60 \%$ de cálcio e $0,57 \%$ de fósforo, respectivamente, são suficientes para a adequada taxa de crescimento e mineralização óssea, quando os minerais estão presentes em formas altamente disponíveis.

Assim, torna-se necessária à avaliação da suplementação destes minerais em rações suplementadas com fitase, principalmente o cálcio, que sofre efeito negativo na sua disponibilidade quando na presença de ácido fítico. Também há que se considerar que o excesso de cálcio na ração prejudica a disponibilidade de outros minerais (Leske \& Coon, 1999), além de afetar negativamente a ação da fitase. Normalmente, não há preocupação dos nutricionistas com o excesso de cálcio na ração em virtude do seu baixo custo e por não apresentar toxicidade, embora alguns trabalhos de pesquisa, como os de Edwards Jr. \& Veltmann (1983), Shafey (1993) e Sebastian et al. (1997) enfatizem seu efeito adverso sobre o desempenho, principalmente na fase inicial de criação.

Portanto, o objetivo do presente trabalho foi determinar o efeito dos níveis de cálcio em rações suplementadas com fitase sobre consumo de ração, ganho de peso, conversão alimentar, digestibilidade da matéria seca, retenção de nitrogênio das aves e deposição de cinzas, cálcio, fósforo, zinco, manganês e magnésio nas tíbias de frangos de corte de 1 a 21 dias de idade.

\section{Material e Métodos}

O experimento foi realizado no Setor de Avicultura da Escola Agrotécnica Federal de Cuiabá (MT). Foram utilizados 600 pintos de corte de um dia, da marca Hubbard-MPK, no período de 1 a 21 dias, alojados em galpão sobre cama, distribuídos em cinco

R. Bras. Zootec., v.32, n.5, p.1190-1197, 2003 
tratamentos e seis repetições, sendo três de cada sexo. Os tratamentos foram dispostos em um delineamento inteiramente casualizado, em esquema fatorial cinco $\mathrm{x}$ dois, sendo cinco níveis de cálcio na ração $(0,46 ; 0,67 ; 0,88 ; 1,09$ e $1,30 \%)$, obtidos pela substituição do caulim da ração basal por calcário e dois sexos. As rações foram isonutritivas, à base de milho e farelo de soja, com $0,54 \%$ de fósforo total, suplementadas com 600 unidades de fitase $/ \mathrm{kg}$, formuladas para atender às exigências nutricionais conforme recomendado pelo NRC (1994), exceto para o cálcio, sendo a composição dos ingredientes obtida de Rostagno et al., (1994). A disponibilidade do fósforo de origem vegetal foi considerada como sendo de $2 / 3$, tendo em vista a suplementação com fitase. A enzima utilizada no experimento foi a Natuphos 5000, fornecida pela BASF, obtida por fermentação por meio de fungos (Aspergillus niger), com atividade mínima declarada pelo fornecedor de $5000 \mathrm{FTU} / \mathrm{g}$. A composição da ração basal pode ser observada na Tabela 1. Ração e água foram fornecidas à vontade e mantido um programa de 24 horas de luz. No período de 18 a 21 dias de idade duas aves de cada parcela foram alojadas em gaiolas de metabolismo para coleta total de excretas, para determinação da digestibilidade da matéria seca da ração e retenção de nitrogênio. A estimativa da excreção endógena e metabólica foi obtida mediante a coleta total de excretas de duas aves por parcela, durante 48 horas após jejum de ração de 24 horas. O material coletado foi acondicionado em sacos plásticos, pesado e armazenado em congelador até o final do período de coleta. Ao final, as excretas foram descongeladas, devidamente reunidas por repetição, homogeneizadas e retiradas alíquotas de 300 a $400 \mathrm{~g}$ para secagem em estufas ventiladas a $55^{\circ} \mathrm{C}$, por 72 horas, quando então foram moídas e acondicionadas para posteriores análises. Aos 21 dias de idade, foram escolhidas aleatoriamente duas aves na média de peso de cada parcela experimental, totalizando 10 aves por tratamento e um total de 60 aves para retirada das tíbias, após abate por deslocamento cervical. Depois de retiradas, as tíbias foram identificadas, descarnadas, desengorduradas, secadas e moídas conforme descrito por Teixeira (1994).

Ingredientes, rações e excretas foram analisados no Laboratório de Pesquisa Animal do DZO/UFLA, segundo metodologia da AOAC (1990). As análises estatísticas dos resultados obtidos foram realizadas de utilizando-se o programa SISVAR (Sistema para
Tabela 1 - Composições percentual e química da ração basal

Table 1 - Precent and chemical composition of the basal diet Ingrediente Percentual (\%)

Ingredient Percent

Milho 53,471

Corn

Farelo de soja $\quad 37,302$

Soybean meal

Óleo de soja

3,663

Soybean oil

Sal

Salt

Premix mineral

0,350

Mineral premix

Premix vitamínico

0,050

Vitamin premix

Monoamônio fosfato $\quad 0,773$

Monoammonium phosphate

Fitase

Phytase

Calcário calcítico

0,400

Limestone

Caulim

0,012

0,841

Composição calculada

Calculated composition

Energia metabolizável (kcal/kg) 3000

Metabolizable energy

Proteína bruta (\%)

21,56

Crude protein

Cálcio $(\%)$

0,46

Calcium

Fósforo disponível (\%) 0,42

Available phosphorus

Metionina (\%)

0,45

Methionine

Metionina + Cistina (\%) $\quad 0,69$

Methionine + Cystine

Lisina (\%)

1,19

Lysine

Triptofano (\%)

Tryptopfan

Treonina $(\%)$

Threonine

0,85

O premix forneceu por kg de ração (The premix supplied per kg of diet): vit. A - $8.000 \mathrm{UI}$; vit. $\mathrm{D}_{3}-2.000 \mathrm{UI}$; vit. $\mathrm{E}-15 \mathrm{UI}$; vit. $\mathrm{K}-1,8 \mathrm{mg}$; Vit. $B_{1}-1,8 \mathrm{mg}$; vit. $B_{2}-6 \mathrm{mg}$; vit. $B_{6} 2,8 \mathrm{mg}$; vit. $B_{12} 12 \mu \mathrm{g}$; Niacina (Niacin) - 40 mg; Ác. fólico' (Folic acid) - $1 \mathrm{mg}$; Âc. pantotênico (Pantothenic acid) - $15 \mathrm{mg}$; Biotina (Biotin) - $60 \mu \mathrm{g}$; Se - 0,3 mg; Colina (Choline) - $400 \mathrm{mg}$; Metionina (Methionine) - 1,2 g; Agente anticoccidiano (Anticocciadial agents) - 0,1 g; Promotor de crescimento (Growth promoter) - 0,06 g; Antioxidante (Antioxidant) - 0,03 g; Mn - $75 \mathrm{mg}$; $\mathrm{Zn}-50 \mathrm{mg} ; \mathrm{Cu}-8 \mathrm{mg} ; \mathrm{I}-0,75 \mathrm{mg}$; Fe - $50 \mathrm{mg}$.

Análises de variância de dados balanceados), desenvolvido por Ferreira (2000). As estimativas de exigências de cálcio foram feitas mediante o uso dos modelos de regressão linear, quadrática e Linear Response Plateau (LRP), descrito por Braga (1983), conforme o ajustamento dos dados obtidos para cada 
variável, interpretando-se as respostas biológicas das aves. As equações do modelo LRP foram obtidas por intermédio do pacote computacional SAEG (Euclydes, 1993). O ajustamento do modelo foi verificado pela soma de quadrados dos desvios, sendo escolhido aquele que apresentou a menor soma de quadrados de desvios.

\section{Resultados e Discussão}

Não houve interação $(P>0,05)$ entre os níveis de cálcio e sexo para as variáveis estudadas (Tabela 2). Os machos tiveram maior consumo de ração $(\mathrm{P}<0,05) \mathrm{e}$ ganho de peso $(\mathrm{P}<0,01)$ do que as fêmeas $(6,17$ e $5,26 \%$ respectivamente), resultados semelhantes aos encontrados por Nelson et al. (1990) e Pizzolante (2000).

Não houve efeito dos níveis de cálcio sobre o consumo de ração e conversão alimentar $(\mathrm{P}>0,05)$, já para o ganho de peso houve redução linear $(\mathrm{P}<0,01)$ conforme os níveis de cálcio na ração foram aumentados.

Estes resultados são semelhantes aos obtidos por Qian et al. (1997), que trabalhando com frangos na fase inicial submetidos a níveis crescentes de cálcio, variando de 0,56 a $1,02 \%$ na ração à base de milho e farelo de soja suplementadas com $600 \mathrm{FTU} / \mathrm{kg}$ de fitase, também observaram redução linear no ganho de peso das aves. Da mesma forma, em experimento com níveis de cálcio variando de 0,93 a $1,23 \%$, e 0,45\% de fósforo disponível, Cabral (1999) também verificou redução do ganho de peso em frangos de $1 \mathrm{a}$ 21 dias, quando o nível de cálcio na ração foi elevado.

Os resultados para ganho de peso obtidos por Cabral (1999), Quian et al. (1997) e deste trabalho demonstram que os menores teores de cálcio das rações proporcionaram os melhores resultados, indicando que a elevação do nível de cálcio na ração, independentemente do uso ou não da fitase, causa redução do ganho de peso. Comparando com as exigências estabelecidas no NRC (1994) para o cálcio, pode se notar que os resultados indicam exigências menores de cálcio do que as preconizadas, no entanto, há que se observar que a relação Ca:P total também é mais estreita, ou seja, com menor teor de fósforo na ração pode-se formular com menor quantidade de cálcio.

Também é importante lembrar que, neste experimento, a utilização da fitase elevou não somente a utilização de fósforo da ração, mas também de cálcio.

Tabela 2 - Consumo de ração, ganho de peso, conversão alimentar dos frangos de 1 a 21 dias e taxa de digestibilidade da matéria seca e taxa de retenção de nitrogênio de 18 a 21 dias de idade, de acordo com os níveis de cálcio da ração

Table 2 - Feed intake, weight gain, feed:gain ratio of the chickens from 1 to 21 days of age, rate of digestibility of the dry matter and rate of retention of nitrogen from 18 to 21 days of age, in agreement with the levels of calcium of the ration

\begin{tabular}{|c|c|c|c|c|c|}
\hline & $\begin{array}{l}\text { Consumo de ração }(\mathrm{g}) \\
\text { Feed intake }\end{array}$ & $\begin{array}{c}\text { Ganho de peso }(\mathrm{g}) \\
\text { Weigth gain }\end{array}$ & $\begin{array}{c}\text { Conversão alimentar }(\mathrm{g} / \mathrm{g}) \\
\text { Feed:gain ratio }\end{array}$ & $\begin{array}{c}\text { Digestibilidade } \\
\text { da matéria seca }(\%) \\
\text { Dry matter } \\
\text { digestibility }(\%)\end{array}$ & $\begin{array}{l}\text { Retenção } \\
\text { de N } \\
\text { Nretention }\end{array}$ \\
\hline Nível de cálcio (\%) & $\mathrm{ns}$ & $*$ & $\mathrm{~ns}$ & $* *$ & $* *$ \\
\hline \multicolumn{6}{|l|}{ Calcium level } \\
\hline 0,46 & 893,7 & 679,2 & 1,3160 & 69,3 & 57,3 \\
\hline 0,67 & 912,2 & 688,5 & 1,3252 & 72,3 & 62,7 \\
\hline 0,88 & 860,0 & 657,8 & 1,3076 & 72,8 & 64,5 \\
\hline 1,09 & 875,7 & 648,5 & 1,3488 & 71,7 & 62,9 \\
\hline 1,30 & 879,8 & 631,3 & 1,3922 & 71,3 & 63,6 \\
\hline Fêmeas & $857,8^{\mathrm{a}}$ & $644,1^{\mathrm{b}}$ & $1,3316^{a}$ & $71,7^{\mathrm{a}}$ & $61,6^{\mathrm{a}}$ \\
\hline \multicolumn{6}{|l|}{ Females } \\
\hline Machos & $910,7^{\mathrm{b}}$ & $678,0^{\mathrm{a}}$ & $1,3449^{a}$ & $71,3^{\mathrm{a}}$ & $62,8^{\mathrm{a}}$ \\
\hline \multicolumn{6}{|l|}{ Males } \\
\hline Média & 884,3 & 661,0 & 1,3380 & 71,5 & 62,2 \\
\hline \multicolumn{6}{|l|}{ Mean } \\
\hline $\mathrm{CV}(\%)$ & 6,78 & 2,78 & 5,44 & 1,81 & 4,54 \\
\hline
\end{tabular}

Médias seguidas de letras diferentes, na mesma coluna, diferem $(P<0,05)$ pelo teste $F$.

Means followed by different letters, within a column, differ $(P<.05)$ by $F$ test.

ns: não-significativo $(P>0,05)$ (ns: not significant $[P>.05])$.

* Efeito linear $(P<0,01)$ (Linear effect $[P<.01])$.

** Efeito quadrático $(P<0,01)$ (Quadratic effect $[P<.01])$.

R. Bras. Zootec., v.32, n.5, p.1190-1197, 2003 
Por outro lado, as exigências de cálcio para esta fase não podem ser estabelecidas apenas com base no melhor ganho de peso, pois deve-se considerar também a adequada mineralização óssea.

A redução no ganho de peso de frangos de corte, em virtude da elevação do nível de cálcio da ração, provavelmente, deve-se ao efeito antagônico que o cálcio causa sobre a absorção de outros minerais e também sobre a ação da fitase. A depressão da atividade fitásica reduz a disponibilidade dos minerais, o que leva à redução da absorção do fósforo e outros minerais complexados com o fitato, que são nutricionalmente importantes (Shafey et al., 1991). A redução da atividade da fitase, em função da elevação do nível de cálcio da ração, também foi comprovada em experimento de Qian et al. (1997).

Os baixos níveis de cálcio $(0,46 \%)$ reduziram a digestibilidade da matéria seca da ração e a retenção de nitrogênio $(\mathrm{P}<0,01)$ sendo que o nível de $0,67 \%$ foi suficiente para atingir a digestibilidade máxima da matéria seca, estimada em $71,5 \%$, e o nível de $0,71 \%$ foi suficiente para maximizar a retenção de nitrogênio em 63,7\%. Rostagno et al. (2000), em experimento com frangos de dez a 19 dias de idade, verificaram que a digestibilidade aparente da matéria seca foi de $68,74 \%$ para os frangos alimentados com ração à base de milho e farelo de soja, com cálcio e fósforo normal e fitase, e de 70,02\% para aqueles submetidos à ração com baixo cálcio e fósforo suplementada com fitase $(0,7 \%$ de cálcio e $0,56 \%$ de fósforo total). A melhora na digestibilidade da matéria seca observada pelos autores acima citados, para os níveis menores de cálcio e fósforo da ração, foram semelhantes aos obtidos neste experimento.

Por outro lado, estes resultados diferem dos encontrados por Sebastian et al. (1996b), que não verificaram efeito do nível de cálcio da ração na retenção de nitrogênio, em frangos de corte de 1 a 21 dias de idade, quando aumentaram o nível de cálcio na ração de 0,66 a $1,25 \%$, suplementada com $600 \mathrm{FTU} / \mathrm{kg}$. Em outro experimento, Sebastian et al. (1997) observaram que a digestibilidade da proteína bruta sofreu redução de 81,8 para $79,85 \%$, ao aumentarem o nível de cálcio da ração de frangos de corte de 0,6 para $1 \%$, em ração com $0,48 \%$ de fósforo total e suplementada com $600 \mathrm{FTU} / \mathrm{kg}$ de ração.

Não houve interação $(\mathrm{P}>0,05)$ entre os níveis de cálcio e sexo e entre os sexos e os níveis de cálcio para a deposição de zinco e magnésio na tíbia dos frangos (Tabela 3). As fêmeas apresentaram deposição de cinzas $(1,68 \%)$ e de cálcio $(2,34 \%)$ superior $(\mathrm{P}<0,05)$ à dos machos, o que difere dos resultados obtidos por Cabral (1999), que não encontrou diferença entre os sexos na mineralização óssea das tíbias.

Tabela 3 - Teor de cinzas, cálcio, fósforo, zinco, manganês e magnésio nas tíbias dos frangos aos 21 dias de idade, na base da matéria seca desengordurada

Table 3 - Content of ashes, calcium, phosphorus, zinc, manganese and magnesium in the tibias of the chickens to21 days of age, on the deffated dry matter basis

\begin{tabular}{|c|c|c|c|c|c|c|}
\hline $\begin{array}{l}\text { Nível cálcio (\%) } \\
\text { Calcium level }\end{array}$ & $\begin{array}{c}\text { Cinzas }(A s h)(\%) \\
* *\end{array}$ & $\begin{array}{c}\mathrm{Ca}(\%) \\
* * *\end{array}$ & $\begin{array}{l}\mathrm{P}(\%) \\
* *\end{array}$ & $\begin{array}{l}\mathrm{Zn}(\mathrm{ppm}) \\
\mathrm{ns}\end{array}$ & $\underset{*}{\operatorname{Mn}(p p m)}$ & $\underset{\mathrm{ns}}{\mathrm{Mg}(\mathrm{ppm})}$ \\
\hline 0,46 & 50,3 & 17,1 & 10,5 & 184,8 & 9,8 & 2857,4 \\
\hline 0,67 & 53,3 & 18,2 & 11,0 & 188,4 & 9,2 & 2824,3 \\
\hline 0,88 & 51,7 & 17,7 & 10,7 & 188,4 & 9,0 & 2617,3 \\
\hline 1,09 & 51,9 & 17,9 & 10,5 & 191,3 & 8,8 & 2584,0 \\
\hline 1,30 & 50,0 & 17,7 & 10,1 & 187,7 & 8,8 & 2463,7 \\
\hline Fêmeas & & & & & & \\
\hline Females & $52,1^{\mathrm{a}}$ & $17,9^{\mathrm{a}}$ & $10,6^{\mathrm{a}}$ & $186,7^{\mathrm{a}}$ & $9,2^{\mathrm{a}}$ & $2628,9^{a}$ \\
\hline Machos & & & & & & \\
\hline Males & $51,2^{\mathrm{b}}$ & $17,5^{\mathrm{b}}$ & $10,5^{\mathrm{a}}$ & $189,6^{\mathrm{a}}$ & $9,0^{\mathrm{a}}$ & $2709,8^{a}$ \\
\hline Média & 51,6 & 17,7 & 10,6 & 188,1 & 9,1 & 2669,4 \\
\hline Mean & & & & & & \\
\hline CV $(\%)$ & 1,93 & 2,45 & 3,47 & 4,28 & 5,19 & 15,78 \\
\hline
\end{tabular}

Médias seguidas de letras diferentes, na mesma coluna, diferem $(P<0,05)$ pelo teste $F$.

Means followed by different letters, within a column, differ $(P<.05)$ by $F$ test.

ns: não-significativo $(P>0,05)$ (ns: not significant $[P>.05])$.

* Efeito linear $(P<0,01)$ (Linear effect $[P<.01])$.

* * Efeito quadrático $(P<0,01)$ (Quadratic effect $[P<.01])$.

*** Efeito quadrático $(P<0,05)$ (Quadratic effect $[P<.05])$.

R. Bras. Zootec., v.32, n.5, p.1190-1197, 2003 
O maior teor de cinzas das tíbias das fêmeas, provavelmente, pode ser atribuído à maturidade sexual mais precoce das fêmeas, devido à ação dos hormônios estrogênicos, que propiciam melhor aproveitamento do cálcio levando a uma calcificação mais intensa na fase inicial (Teixeira 1994). Houve efeito $(\mathrm{P}<0,01)$ para níveis de cálcio sobre os teores de cinzas e $\mathrm{Ca}$ nas tíbias.

Pelo modelo Linear Response Plateu (LRP), a deposição máxima de minerais nas tíbias aos 21 dias de idade, foi estimada em 51,5\%, com $0,55 \%$ de cálcio na ração. Qian et al. (1997) estimaram que o nível de $0,71 \%$ de cálcio na ração resultou na melhor mineralização óssea de frangos de corte de 1 a 21 dias, alimentados com ração à base de milho e farelo de soja, com $0,51 \%$ de fósforo total e níveis de cálcio variando de 0,56 a $1,02 \%$ e suplementada com 600 FTU/kg. Já Mitchell \& Edwards Jr. (1996b) verificaram elevação no teor de cinzas da tíbia em frangos de 1 a 21 dias, quando aumentaram o nível de cálcio da ração de 0,63 a $0,99 \%$ em rações à base de milho e farelo de soja contendo $0,55 \%$ de fósforo total e suplementada com $600 \mathrm{FTU} / \mathrm{kg}$.

O teor de cálcio na tíbia, no nível de $0,46 \%$ de cálcio da ração, foi inferior, indicando que o mesmo não foi suficiente para promover adequada calcificação, conforme indicado na Tabela 3. Os teores de cálcio nas tíbias foram crescentes conforme o nível de cálcio foi aumentado, estabilizando-se no nível de $17,8 \%$, quando a ração continha $0,59 \%$ de cálcio, segundo a estimativa obtida no modelo LRP.

Schoner et al. (1993), avaliando rações deficientes em fósforo contendo níveis de 0,$60 ; 0,75$ e $0,90 \%$ de cálcio, observaram aumento na deposição de cálcio e fósforo em frangos de corte submetidos a rações com baixo nível de cálcio suplementada com fitase, já os tratamentos com níveis altos de cálcio e com fitase afetaram negativamente a deposição do fósforo e cálcio.

Sebastian et al. (1996b) não verificaram influência significativa do nível de cálcio da ração na retenção de cálcio no osso, em frangos de corte de 1 a 21 dias de idade, quando aumentaram o nível de cálcio da ração de 0,66 a 1,25\%, em ração suplementada com $600 \mathrm{FTU} / \mathrm{kg}$.

Houve efeito quadrático nos teores de fósforo na tíbia $(\mathrm{P}<0,01)$, com a deposição máxima estimada em
$10,83 \%$, com $0,75 \%$ de cálcio na ração. Sebastian et al. (1996a), trabalhando com frangos de corte de $1 \mathrm{a}$ 21 dias, testaram o efeito de três níveis de cálcio na ração $(0,60,1$ e 1,25\%) suplementada com 600 FTU/ $\mathrm{kg}$ de fitase e observaram que a retenção de fósforo foi maior com $1 \%$, em comparação a 0,60 e 1,25\%. Isso demonstra que o excesso de cálcio na ração prejudicou o aproveitamento do fósforo, provavelmente reduzindo a utilização do fósforo fítico, devido à formação de complexos insolúveis com o cálcio no trato digestivo, anulando o efeito da fitase, uma vez que a mesma não é capaz de hidrolisar estes complexos (Leeson, 1999).

Estes resultados mostram claramente que a exigência de cálcio para frangos, em rações com baixo fósforo e fitase, é inferior à exigência recomendada pelas tabelas de exigências nutricionais, indicando que a redução do nível de cálcio da ração deve ser proporcional à redução do nível de fósforo total promovido em virtude da utilização da fitase, mantendo-se, desta forma, uma relação $\mathrm{Ca}: \mathrm{P}$ adequada. Sebastian et al. (1996b) verificaram influência significativa do nível de cálcio da ração sobre o teor de fósforo na tíbia, em frangos de corte de 1 a 21 dias de idade, com redução linear do teor de fósforo na cinza da tíbia, quando aumentaram o nível de cálcio da ração de 0,66 a $1,25 \%$, em ração suplementada com $600 \mathrm{FTU} / \mathrm{kg}$ de ração.

Houve efeito linear dos níveis de cálcio $(\mathrm{P}<0,01)$ sobre a deposição de manganês na tíbia. Estes dados diferem dos encontrados por Sebastian et al. (1996b), que não verificaram influência significativa do nível de cálcio sobre o conteúdo de manganês nas cinzas da tíbia, em frangos de corte de 1 a 21 dias de idade, quando aumentaram o nível de cálcio de 0,60 a 1,25\%, em ração suplementada com 600 FTU/kg. A redução da deposição de manganês nos ossos, possivelmente, se deve à drástica redução da absorção do mesmo para as aves que consumiram ração com nível elevado de cálcio.

$\mathrm{Na}$ Tabela 4, é apresentado um resumo das equações obtidas para as diferentes variáveis estudadas, em que houve diferença $(\mathrm{P}<0,05)$, em função dos níveis de cálcio na ração, bem como o (X) máximo (nível de cálcio na ração) que proporciona o melhor resultado (Y) para a variável em questão, obtido pela derivação da equação. 
Tabela 4 - Equações obtidas para as variáveis em que houve diferença significativa, em função do nível de cálcio na ração Table 4 - Equations obtained for the variables where there was significant difference, in function of the level of calcium in the diet

\begin{tabular}{|c|c|c|c|c|c|}
\hline $\begin{array}{l}\text { Variável } \\
\text { Variable }\end{array}$ & $\begin{array}{l}\text { Modelo } \\
\text { Model }\end{array}$ & $\begin{array}{l}\text { Equação } \\
\text { Equation }\end{array}$ & $\mathrm{R}^{2}$ & $\begin{array}{l}\text { Máximo } \mathrm{X} \\
\text { Maximum } X\end{array}$ & $\begin{array}{l}\text { Máximo Y } \\
\text { Maximum } Y\end{array}$ \\
\hline $\begin{array}{l}\text { Ganho de peso }(\mathrm{g}) \\
\text { Weight gain }(\mathrm{g})\end{array}$ & Linear & $\hat{Y}=717,92-64,603 X$ & 0,86 & 0,46 & 688,2 \\
\hline $\begin{array}{l}\text { Digestibilidade da matéria seca (\%) } \\
\text { Dry matter digestibility (\%) }\end{array}$ & Quadrático & $\hat{Y}=60,7+25,647-13,681 X^{2}$ & 0,85 & 0,93 & 72,7 \\
\hline $\begin{array}{l}\text { Digestibilidade da matéria seca (\%) } \\
\text { Dry matter digestibility (\%) }\end{array}$ & LRP & $\hat{\mathrm{Y}}=65,883+8,333 \mathrm{X}$ & 0,85 & 0,67 & 71,5 \\
\hline $\begin{array}{l}\text { Retenção de nitrogênio (\%) } \\
\text { Nitrogen retention (\%) }\end{array}$ & Quadrático & $\hat{Y}=42,493+42,838 X-20,864 X^{2}$ & 0,88 & 1,02 & 64,5 \\
\hline $\begin{array}{l}\text { Retenção de nitrogênio (\%) } \\
\text { Nitrogen retention (\%) }\end{array}$ & LRP & $\hat{\mathrm{Y}}=45,471+25,741 \mathrm{X}$ & 0,96 & 0,71 & 63,7 \\
\hline $\begin{array}{l}\text { Cinza na tíbia (\%) } \\
\text { Ash in the tíbia (\%) }\end{array}$ & Quadrático & $\hat{\mathrm{Y}}=44,889+17,286 \mathrm{X}-9,8154 \mathrm{X}^{2}$ & 0,52 & 0,88 & 52,5 \\
\hline $\begin{array}{l}\text { Cinza na tíbia }(\%) \\
\text { Ash in the tibia (\%) }\end{array}$ & LRP & $\hat{\mathrm{Y}}=43,709+14,286 \mathrm{X}$ & 0,91 & 0,55 & 51,5 \\
\hline $\begin{array}{l}\text { Cálcio na tíbia (\%) } \\
\text { Calcium in the tibia (\%) }\end{array}$ & Quadrático & $\hat{\mathrm{Y}}=15,412+5,33 \mathrm{X}-2,7724 \mathrm{X}^{2}$ & 0,51 & 0,96 & 18 \\
\hline $\begin{array}{l}\text { Cálcio na tíbia (\%) } \\
\text { Calcium in the tibia (\%) }\end{array}$ & LRP & $\hat{\mathrm{Y}}=14,864+4,905 \mathrm{X}$ & 0,94 & 0,59 & 17,7 \\
\hline $\begin{array}{l}\text { Fósforo na tíbia (\%) } \\
\text { Phosphorus in the tíbia (\%) }\end{array}$ & Quadrático & $\hat{\mathrm{Y}}=9,331+4 \mathrm{X}-2,662 \mathrm{X}^{2}$ & 0,86 & 0,75 & 10,8 \\
\hline $\begin{array}{l}\text { Manganês na tíbia (ppm) } \\
\text { Manganese in the tíbia (ppm) }\end{array}$ & Linear & $\hat{\mathrm{Y}}=10,127-1,154 \mathrm{X}$ & 0,87 & 0,46 & 9,6 \\
\hline
\end{tabular}

\section{Conclusões}

Em rações iniciais à base de milho e farelo de soja para frangos de corte suplementada com fitase, a elevação dos níveis de cálcio da ração afetou negativamente o ganho de peso e os níveis mais baixos reduziram a digestibilidade da matéria seca e a retenção de nitrogênio, indicando que os níveis de cálcio devem ser reduzidos proporcionalmente à redução dos níveis de fósforo total.

O melhor ganho de peso foi estimado para $0,46 \%$ de cálcio na ração suplementada com fitase.

O nível de $0,59 \%$ de cálcio proporcionou adequada mineralização óssea, enquanto a deposição de cinza, fósforo e manganês na tíbia diminuiu com a elevação dos teores de cálcio nas rações.

\section{Literatura Citada}

ASSOCIATION OF OFFICIAL ANALYTICAL CHEMIST AOAC. Official methods of analysis. 15.ed. Washington, D.C.: $1990.684 \mathrm{p}$.

BALLAM, G.C.; ENGSTER, H.M.; SNETZINGER, D.C. Effect of calcium level on the ability of broiler and single comb White leghorn to hydrolyze phytate phosphorus. Poultry Science, v.63, p.61, 1984. (abstract)

\footnotetext{
R. Bras. Zootec., v.32, n.5, p.1190-1197, 2003
}

BORGES, F.M.O. Utilização de enzimas em dietas avícolas. Cadernos Técnicos da Escola de Veterinária da UFMG, v.20, p.5-30, 1997.

BRAGA, J.M. Avaliação de fertilidade do solo (ensaios de campo). Viçosa, MG: Universidade Federal de Viçosa, 1983. p.101. (Publicação, 156).

CABRAL, G.H. Níveis de cálcio em rações para frango de corte. Viçosa, MG: Universidade Federal de Viçosa, 1999. 107p. Tese (Doutorado em Zootecnia) - Universidade Federal de Viçosa, 1999.

DENBOW, D.M.; RAVINDRAN, V.; KORNEGAY; YI, Z. et al. Improving phosphorus availability in soybean meal for broilers by supplemental phytase. Poultry Science, v.74, n.11, p.1831-1842, 1995.

EDWARDS Jr., H.M.; VELTMANN, J.r. The role of calcium and phosphorus in the etiology of tibial dyscondroplasia in young chicks. Journal of Nutrition, v.113, n.8, p.15681575, 1983.

EUCLYDES, R.F. Sistema de analises estatísticas e genéticas - SAEG x guia do usuário. Viçosa, MG: Universidade Federal de Viçosa, 1993.

FERREIRA, D.F. Sistema de análise estatística para dados balanceados (SISVAR). Lavras, MG: Universidade Federal de Lavras/DEX. 2000.

KARUNAJEEWA, H. Effect of some feed additives on the performance of broiler chicks fed diets containing high levels of meat and bone meal. Australian Journal of Experimental Agriculture and Animal Husbandry, v.16, p.685-690, 1976.

LEESON, S. Enzimas para aves. In: SIMPÓSIO INTERNACIONAL SOBRE NUTRIÇÃO DE AVES, FACTA, 1999, Campinas. Anais... Campinas: FACTA, 1999. p.173-185. 
LESKE, K.L.; COON, C.N. A Bioassay to determine the effect of phytase on phytate phosphorus hydrolysis and total phosphorus retention of feed ingredients as determined with broilers and laying hens. Poultry Science, v.78, n.8, p.11511157, 1999.

MITCHELL, R.D.; EDWARDS Jr., H.M. Additive effects of 1,25-dihidroxicholecalciferol and phytase on phytate phosphorus utilization and related parameters in broiler chickens. Poultry Science, v.75, n.1, p.111-119, 1996a.

MITCHELL, R.D.; EDWARDS Jr., H.M. Effects of phytase and 1,25-Didroxicholecalciferol on phytate utilization and quantitative requirement for calcium and phosphorus in young broiler chickens. Poultry Science, v.75, n.1, p.111119, 1996b.

NATIONAL RESEARCH COUNCIL - NRC. Nutrient requirements of poultry. 9.ed. Washington, D.C.: National Academy of Science, 1994. 155p.

NELSON, T.S.; HARRIS, G.C.; JOHNSON, Z.B. Effect of calcium and phosphorus on the incidence of leg abnormalities in growing broilers. Poultry Science, v.69, n.9, p.1496$1502,1990$.

PIZZOLANTE, C.C. Estudo da atividade enzimática da fitase e sua utilização na alimentação de frangos de corte. Lavras: MG, Universidade Federal de Lavras, 2000. 127p. Tese (Doutorado em Zootecnia) - Universidade Federal de Lavras, 2000.

QIAN, H.; KORNEGAY, E.T.; DENBOW, D.M. Utilization of phytate phosphorus and calcium as influenced by microbial phytase, cholecalciferol, and the calcium: total phosphorus ratio in broiler diets. Poultry Science, v.76, n.5, p.37-46, 1997.

ROSTAGNO, H.S. Exigências nutricionais e biodisponibilidade de fósforo para frangos de corte. In: SIMPÓSIO INTERNACIONAL SOBRE NUTRIÇÃO DE AVES, 1998, Campinas. Anais... Campinas: Colégio Brasileiro de Nutrição Animal, 1998. p.1-27.

ROSTAGNO, H.S.; SILVA, D.J.; COSTA, P.M.A. et al. Composição de alimentos e exigências nutricionais de aves e suínos (Tabelas Brasileiras). Viçosa, MG: Universidade Federal de Viçosa, 1994. 59p.

ROSTAGNO, H.S.; TEJEDOR, A.A.; ALBINO, L.F.T. et al. Enzyme supplementation of corn and soy bean meal diets improves ileal digestibility of nutrients in broiler chicks. In: ALLTECH'S ANNUAL SYMPOSIUM OF BIOTECHNOLOGY IN THE FEED INDUSTRY, 16., 2000, Nottingham. Proceedings... Nottingham: 2000. p.175-182.
SCHONER, F.P.; HOPPE, P.P.; SCHWARZ, G. et al. Effects of microbial phytase and inorganic phosphate in broiler chickens: performance and mineral retention at various calcium levels. Journal of Animal Physiology and Animal Nutrition, v.69, p.235-244, 1993.

SEBASTIAN, S.; TOUCHBURN, S.P.; CHAVEZ, E.R. et al. The effects of supplemental microbial phytase on the performance and utilization of dietary calcium, phosphorus, copper, and zinc in broiler chickens fed corn-soybeans diets. Poultry Science, v.75, n.6, p.729-736, 1996a.

SEBASTIAN, S.; TOUCHBURN, S.P.; CHAVEZ, E.R. et al. Efficacy of supplemental microbial phytase at different dietary calcium levels on growth performance and mineral utilization of broiler chickens. Poultry Science, v.75, n.12, p.1516-1523, $1996 \mathrm{~b}$.

SEBASTIAN, S.; TOUCHBURN, S.P.; CHAVEZ, E.R. et al. Apparent digestibility of protein and amino acids in broiler chickens fed a corn-soybean diet supplemented with microbial phytase. Poultry Science, v.76, n.12, p.1760-1769, 1997.

SHAFEY, T.M. Calcium tolerance of growing chickens: effect of ratio of dietary calcium to available phosphorus. Word's Poultry Science Journal, v.49, n.1, p.5-18, 1993.

SHAFEY, T.M.; McDONALD, M.W.; DINGLE, J.G. Effects of dietary calcium and available phosphorus concentration on digesta $\mathrm{pH}$ and on the availability of calcium, iron, magnesium and zinc from the intestinal contents of meat chickens. British Poultry Science, v.32, n.1, p.185-194, 1991.

TEIXEIRA, A.S. Exigências nutricionais de zinco e sua disponibilidade em sulfatos e óxidos de zinco para pintos de corte. Porto Alegre: Universidade Federal do Rio Grande do Sul, 1994. 172p. Tese (Doutorado em Zootecnia) - Universidade Federal do Rio Grande do Sul, 1994. 